\title{
Distribution of fibronectin and laminin in normal and pathological lymphoid tissue
}

\author{
JT REILLY, JR NASH, ${ }^{*}$ MJ MACKIE, BA MCVERRY \\ From the University Departments of Haematology and *Pathology, Royal Liverpool Hospital, Liverpool
}

SUMMARY Forty six lymph nodes were examined with the indirect immunoperoxidase technique for the distribution of fibronectin and laminin. Fibronectin was present in the framework of the tissue and the basal lamina of blood vessels, giving a clear ouline of nodal architecture. Intracellular fibronectin was observed in cases of reactive sinus histiocytosis, when about a third of macrophages exhibited strong positivity. Mast cells were positive. A pronounced increase in extracellular fibronectin was seen in nodular sclerosing Hodgkin's disease, although heavily hyalinised areas exhibited only superficial positivity. Reed-Sternberg and mononuclear Hodgkin's cells were consistently negative for fibronectin. Laminin staining was localised to vascular and marginal sinus basement membranes. No cellular positivity was evident. The distribution of laminin indicated a pronounced increase in vascularity in nodular sclerosing Hodgkin's disease, which was especially prevalent within the dense fibrous trabeculae. In contrast, however, examination of the other Rye subtypes showed a lesser degree of vascularity with numbers of vessels similar to those observed in reactive follicular hyperplasia. Laminin was found to be more efficient than factor VIII related antigen as a vascular marker.

Fibronectin and laminin are both non-collagenous connective tissue glycoproteins of high molecular weight. ${ }^{2}$ Fibronectin is widely distributed throughout the body and is found in basement membranes and loose connective tissue. Although its distribution differs from that of collagen and elastic fibres, its relation to reticulin remains unclear. ${ }^{3-5}$ It has been found in several cell types including fibroblasts, macrophages, megakaryocytes, and platelets as well as plasma. ${ }^{-10}$ Laminin, however, is localised to the basal lamina of only epithelial, mesenchymal, and endothelial cells. ${ }^{11} 12$ Current interest in both glycoproteins centres on their altered distribution in malignant conditions. Stromal fibronectin is increased in most carcinoma tissue,,$^{13}$ while surface fibronectin may be lost from cells after oncogenic transformation. ${ }^{14}$ Loss of laminin and disruption of basement membrane structure appear important for the detachment of tumour cells and metastatic development. ${ }^{15}$ In addition, the egression of metastasising cells from the circulation may be mediated in part through receptors to laminin on the surface of cells. ${ }^{16}$

We have not discovered any previous studies on the distribution of laminin in pathological lymphoid

Accepted for publication 2 April 1985 tissue. Studies on fibronectin have been confined to Hodgkin's disease and have produced conflicting results. Resnick and Nackman reported cytoplasmic fibronectin in Reed-Sternberg cells and presented this as evidence for their monocyte and macrophage lineage. ${ }^{17}$ In contrast Moller et al concluded that both Reed-Sternberg and Hodgkin's cells probably neither synthesise nor bind fibronectin. ${ }^{18}$ Both proteins are detectable in sections fixed in formalin and embedded in paraffin using specific antibodies. In the case of laminin, however, pretreatment of the tissue sample with proteolytic enzymes is required before it can be detected. ${ }^{19}$ We have used these methods, therefore, to determine the distributions of fibronectin and laminin in normal and pathological lymphoid tissue.

\section{Material and methods}

We used rabbit antihuman fibronectin obtained from Dakopatts A/S (A245) and rabbit antimouse laminin kindly donated by Dr Roberts, Bethesda Research Laboratories (BRL 6265SA). Peroxidase conjugated swine antirabbit antiserum was also obtained from Dakopatts A/S (P217). All antibodies were diluted $1 / 40$ in phosphate buffered 
saline $\mathrm{pH} \mathrm{7.4}$ before use. $\mathrm{T}$ and $\mathrm{B}$ cell nonHodgkin's lymphomas had been previously classified using mouse monoclonal antibodies applied to frozen sections. The range used included anti-IgM, anti-IgD, anti-DRC, and anti-T cell (helper and suppressor), all obtained from Dakopatts A/S. The remaining materials were obtained from BDH Chemicals Ltd, Poole, England.

\section{TISSUES}

Forty six paraffin embedded sections were examined. The table shows the histological dianosis. Specimens were fixed for 24 hours in $10 \%$ neutral buffered formol saline ${ }^{19}$ and routinely processed to paraffin wax.

\section{METHOD}

(i) Sections $(3 \mu \mathrm{m})$ were rehydrated with xylene and alcohol. (ii) Endogenous peroxidase activity was blocked by treating the sections in $0.3 \%$ hydrogen peroxide in methanol for 30 minutes at room temperature. (iii) Sections were washed in phosphate buffered saline for five minutes and then treated with $0.05 \%$ protease type VII (Sigma, P-5255) in phosphate buffered saline for 20 minutes at $37^{\circ} \mathrm{C}$.

Classification of lymphoid tissue examined with indirect immunoperoxidase technique

\begin{tabular}{lc}
\hline Diagnosis & No of sections \\
\hline Reactive follicular hyperplasia & 8 \\
Reactive sinus histiocytosis & 2 \\
Tonsil & 3 \\
Angiofollicular hyperplasia & 1 \\
Hodgkin's disease & 24 \\
Nodular sclerosis & 10 \\
Mixed cellularity & 8 \\
Lymphocyte predominant & 4 \\
Lymphocyte depleted & 2 \\
Non-Hodgkin's lymphoma & 8 \\
T cell & 2 \\
B cell & 6 \\
\hline
\end{tabular}

Digestion was stopped in cold running tap water. (iv) The sections were then washed and treated with normal swine serum in phosphate buffered saline (1/5 dilution) for five minutes. (v) Primary antibodies (1/40) were applied at room temperature for 30 minutes. (vi) The sections were washed in phosphate buffered saline for 15 minutes (three changes) and incubated with swine antirabbit IgG peroxidase conjugated ( $1 / 40)$ for 30 minutes, with a subsequent wash in phosphate buffered saline. (vii) The sections were then rinsed in $3,3^{\prime}$ diaminobenzidine $/ \mathrm{H}_{2} \mathrm{O}_{2}$ and counterstained where appropriate with Mayer's haematoxylin. (viii) Finally, the sections were dehydrated in ethanol, rinsed in xylene, and mounted in Kirkpatrick and Lendrum's DPX for preservation.

\section{CONTROLS}

Substitution of primary antibody with non-immune rabbit IgG or phosphate buffered saline produced negative staining. Negative reactions were also observed with inappropriate primary antibodies. The blocking of endogenous peroxidase activity with methanol was shown not to affect the antigenicity of fibronectin, laminin, and factor VIII related antigen.

\section{Results}

\section{FIBRONECTIN}

Antifibronectin antibody produced a reticular pattern of staining in addition to outlining the vascular basement membranes in all tissues. In lymph nodes showing reactive follicular hyperplasia an interfollicular, web like extracellular network of fibronectin was present. By contrast, the follicles contained scanty fibronectin limited to a few fibrils and occasional staining in blood vessel walls. In these nodes marginal sinus basement membranes were positive and heavy staining was present in node capsules. Similar results were obtained in tonsillar tissue and

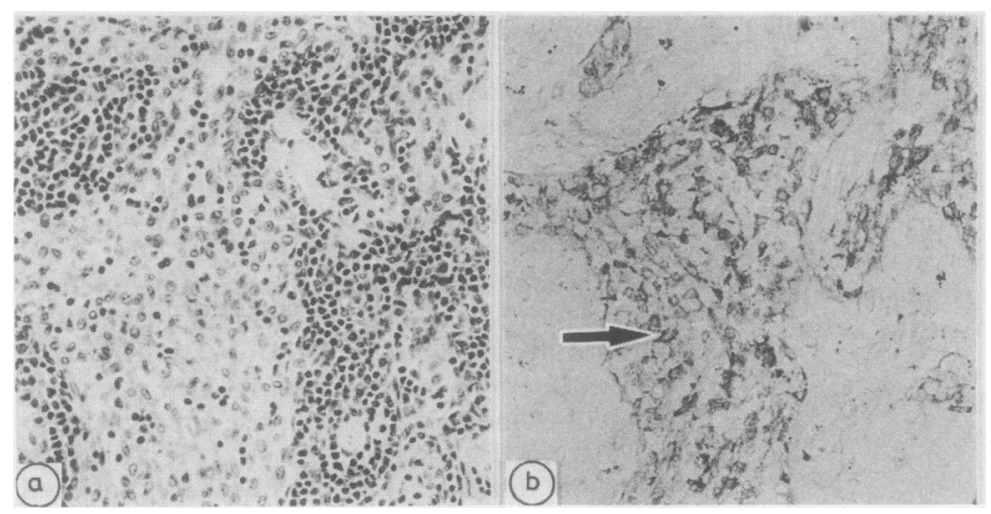

Fig. 1 Reactive sinus histiocytosis. (a) Haematoxylin and eosin. $\times 150$. (b) Stained for fibronectin. Note presence of strongly staining histiocytes (arrowed). $\times 150$. 


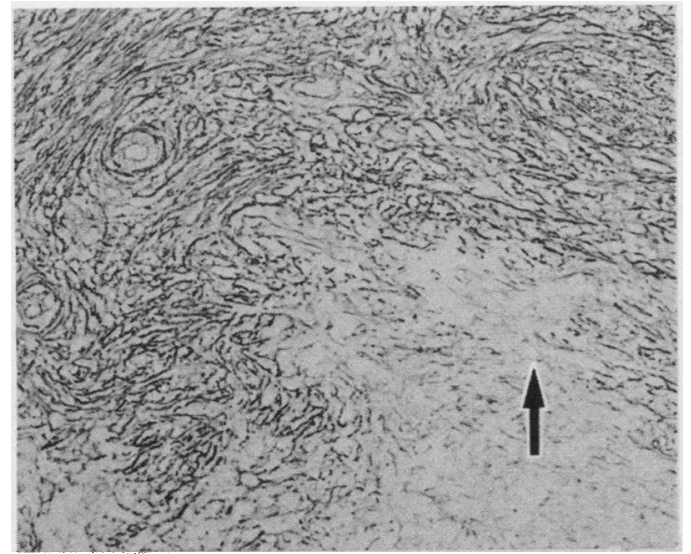

Fig. 2 Nodular sclerosing Hodgkin's disease showing dense fibronectin staining in areas of sclerosis. Note minimal staining pattern in an area of hyalinisation (arrowed). $\times 150$.

in a lymph node showing angiofollicular hyperplasia, although the lymph node contained increased numbers of small blood vessels in the interfollicular tissue. Cellular fibronectin was confined to mast cells and was not observed in lymphocytes, neutrophils, or macrophages. By contrast, lymph nodes showing reactive sinus histiocytosis possessed considerable cellular positivity confined to areas of histiocytic hyperplasia, $20-30 \%$ of these cells reacting strongly (Fig. 1).

A considerable difference was observed in stromal fibronectin content between the subtypes of Hodgkin's disease. Lymph nodes showing nodular sclerosing Hodgkin's disease contained increased quantities of fibronectin. Dense staining was seen within the bands of sclerotic tissue (Fig. 2), although hyalinised tisse exhibited only surface staining. Mixed cellularity, lymphocyte depleted, and lymphocyte predominant subtypes did not have increased stromal fibronectin. Reed-Sternberg and mononuclear "Hodgkin's cells" were consistently negative. In all cases of Hodgkin's disease and non-Hodgkin's lymphoma the disruption in nodal architecture was clearly visible.

\section{LAMININ}

In lymph nodes laminin was localised to vascular and marginal sinus basement membranes only (Fig. 3) and was found to be a suitable vascular marker. In reactive follicular hyperplasia staining was essentially confined to interfollicular areas with few vessels staining within the follicle centres (Fig. 4). Tonsillar tissue, while highlighting the perifollicular vascular distribution more clearly, also showed strong staining of cryptal epithelial basement membrances. Blood vessels in angiofollicular hyperplasia stained strongly, including those within the follicle centres (Fig. 5). Laminin staining in Hodgkin's disease showed a considerable increase in vascularity in the nodular sclerosing subtype. This

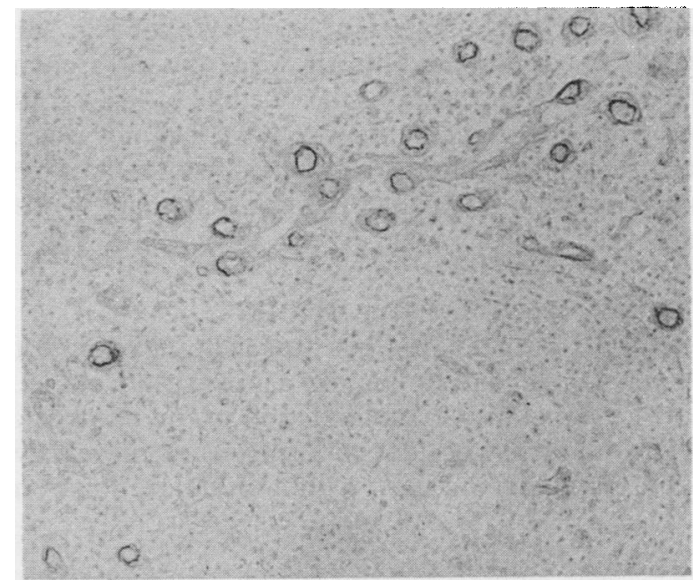

Fig. 4 Reactive follicular hyperplasia. Laminin staining is essentially confuned to blood vessels within the interfollicular areas. Few vessels are present within follicle centres. $\times 150$.

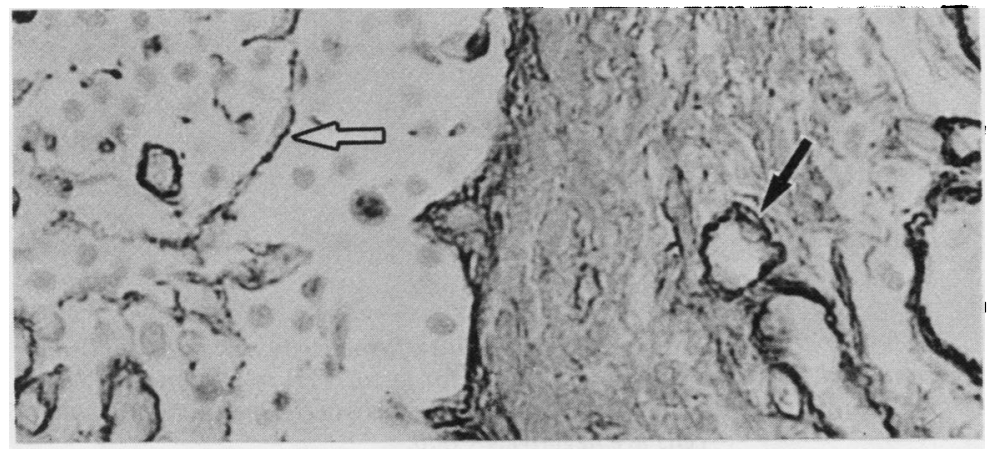

Fig. 3 Marginal sinus of reactive lymph node (follicular hyperplasia). Laminin is localised to vascular (single arrow) and marginal sinus basement membranes (double arrow) only. $x$ 600. 


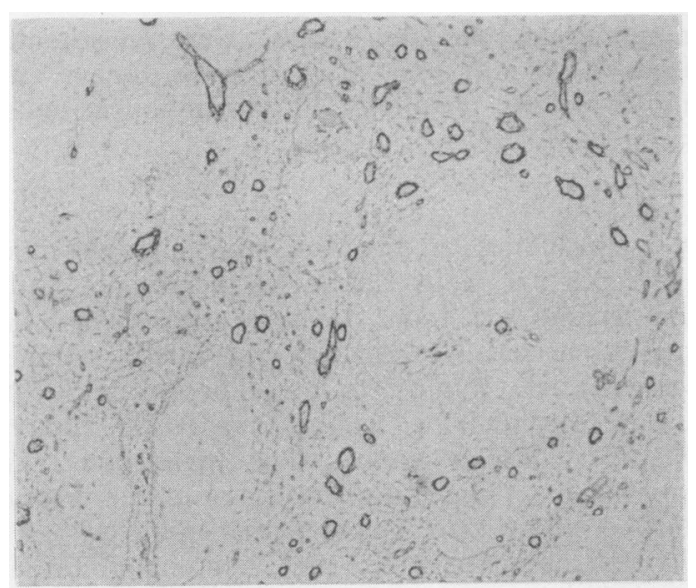

Fig. 5 Angiofollicular hyperplasia stained for laminin. $\times$ 150.

was widespread and most pronounced within areas of dense fibrous tissue (Fig. 6). The other Rye subtypes, by contrast, did not show increased vascularity (Fig. 7). In all sections the residual follicles could be clearly identified by their relative lack of vasculature. In sections of non-Hodgkin's lymphoma $T$ cell tumours had a greater vascularity than B cell tumours.

\section{FACTOR VIII RELATED ANTIGEN}

Factor VIII related antigen was generally found to be less effective than laminin as a vascular marker, both in the clarity of staining and in the number of vessels stained. Vascular endothelial cells in reactive hyperplasia stained best, with a moderate to strong

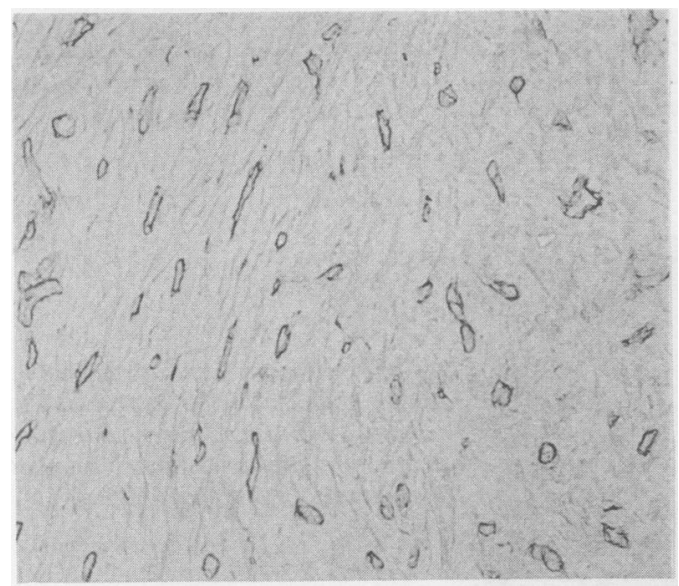

Fig. 6 Nodular sclerosing Hodgkin's disease stained for laminin (same specimen as Fig. 2). Note presence of increased vascularity. $\times 150$.

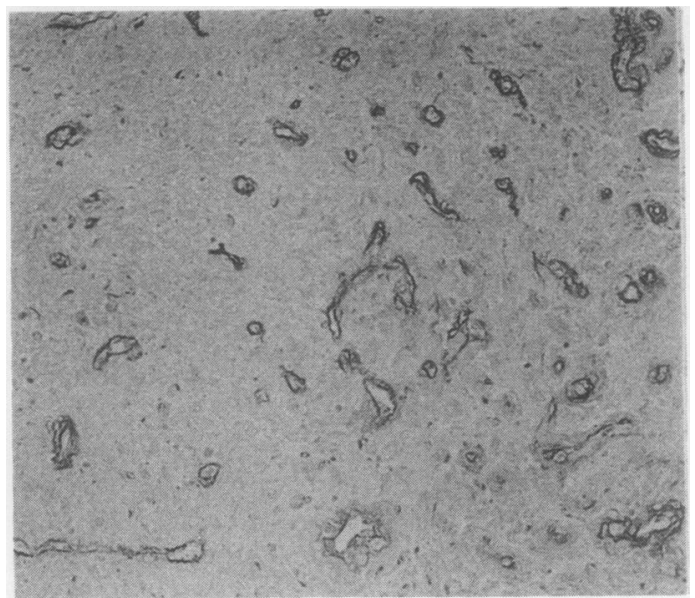

Fig. 7 Specimen of lymphocyte depleted Hodgkin's disease stained for laminin. $\times 150$.

granular positivity. Varying degrees of staining were shown in some pathological specimens. In contrast to vascular endothelial cells, marginal sinus lining cells were uniformly negative (Fig. 8).

\section{Discussion}

The distribution of fibronectin in lymphoid tissue correlated, as reported by Stenman and Vaheri, ${ }^{3}$ with basement membranes and reticulin fibres. Of particular interest, however, was the finding of increased deposition of fibronectin in nodular sclerosing Hodgkin's disease. Experimental evidence shows that deposition of fibronectin may facilitate the ingrowth of fibroblasts and subsequent

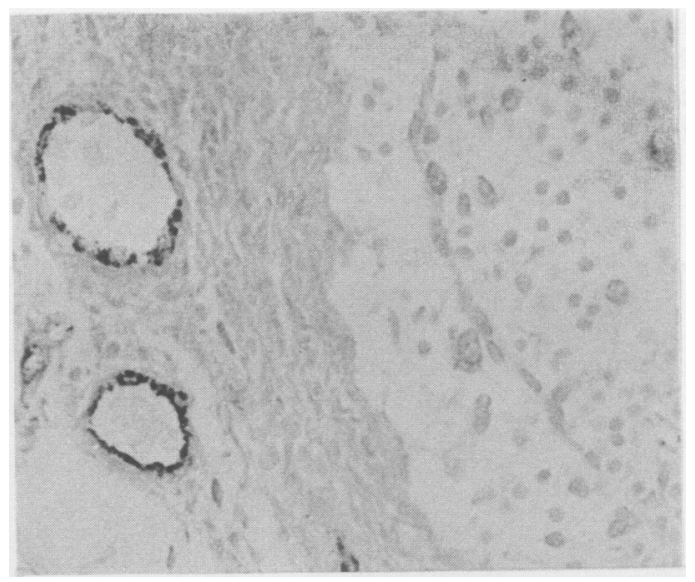

Fig. 8 Marginal sinus of reactive lymph node (follicular hyperplasia) stained for factor VIII related antigen. In contrast to vascular endothelial cells marginal sinus lining cells are negative. $\times 600$. 
formation of fibrous tissue. ${ }^{20}$ Wound healing models have shown that the synthesis of fibronectin occurs early in the formation of granulation tissue together with invading fibroblasts. Synthesis of collagen occurs later, and once organised into larger bundles both fibroblasts and fibronectin can no longer be seen. ${ }^{20}$ This observation may account for the minimal staining of fibronectin seen in heavily hyalinised areas. In contrast to nodular sclerosing Hodgkin's disease, all other pathological lymph nodes examined showed similar patterns of fibronectin staining, suggesting that fibronectin does not play a major part in their pathogenesis. The vascular reaction seen in nodular sclerosing Hodgkin's disease may in some way induce synthesis of collagen in the stroma. ${ }^{21}$ Interestingly, we have described a similar increase in both fibronectin and vascularity in myelofibrosis. ${ }^{822}$ It remains to be determined, however, whether this increased vascularity represents a primary or secondary phenomenon.

The localisation of cellular fibronectin in our study was limited to mast cells and reactive histiocytoses. Mast cell staining has been reported by several authors, ${ }^{18}{ }^{23}$ although whether it is true staining or an artefact remains uncertain. Macrophages are known to synthesise and secrete fibronectin, a function thought to be related to their phagocyte activity. ${ }^{24}$ One study reported that about a third of mononuclear cells from peritoneal exudates induced by oil, stained for fibronectin. ${ }^{25}$ While we could not detect fibronectin within normal lymph node macrophages, one third of the histiocytes in areas of sinus histiocytosis possessed strong positivity. This would suggest that histiocytic fibronectin synthesis may occur as a result of antigenic stimulation and subsequent proliferation. Resnick and Nachman reported the presence of abundant cytoplasmic fibronectin in Reed-Sternberg cells ${ }^{17}$ and, as lymphocytes neither contain nor sythesise fibronectin, used this as evidence for their macrophage origin. This conclusion, however, conflicts with the mounting evidence for a lymphocytic lineage for ReedSternberg cells (unpublished findings). We have not been able to confirm this finding and would agree with Moller et al that Hodgkin's and ReedSternberg cells probably neither produce nor bind fibronectin. ${ }^{18}$

In this study laminin staining was limited to basement membranes and was found to be an ideal vascular marker. Its reliability and effectiveness was compared with that of factor VIII related antigen, an established marker for vascular endothelial cells. Although factor VIII related antigen has been identified with various immunological techniques in tissue sections ${ }^{26}{ }^{27}$ and cultured endothelial cells, ${ }^{28}$ it is not specific for the endothelial cell, found in platelets and megakaryocytes. ${ }^{29}{ }^{30}$ Bloom and Giddings pointed out that most commercial factor VIII related antigen antisera are not necessarily specific and may well be contaminated with additional antibodies. ${ }^{31}$ While normal blood vessels stain satisfactorily, varying degrees of positivity are seen in certain pathological conditions ${ }^{26}$ : this limitation has been noted in pathological lymphoid tissue. Jones et al found weak staining of the abnormal vessels within follicle centres in a study of angiofollicular hyperplasia. ${ }^{32}$ The result of our study would suggest that laminin is a more efficient vascular marker than factor VIII related antigen as most vessels, including those in angiofollicular hyperplasia, stained uniformly and strongly.

The localisation of laminin confirmed the reported increase in vascularity of nodular sclerosing Hodgkin's disease, especially within the dense fibrous trabeculae. ${ }^{21}$ In contrast to this earlier study, however, we did not find a deficiency of vessels in the other Rye subtypes when compared with reactive follicular hyperplasia. Similar conclusions were obtained using antifactor VIII related antigen antibodies despite this being less effective as a vascular marker. These findings were consistent in all sections examined; the reason for the difference between our results and those of Crocker and Smith ${ }^{21}$ is unclear.

A diagnostic feature of $T$ cell lymphoma is reported to be an increase in vascularity compared with B cell lymphoma. ${ }^{33}$ This was confirmed in our small series, although laminin and factor VIII related antigen showed more vessels in both $T$ and $B$ cell lymphomas than was suggested on routine staining with haematoxylin.

We thank Mr A Williams for his help with photography and Miss Helen Dimmock for secretarial help. This study was financially supported by the Carol Shepherd Fund and Mersey Regional Health Authority.

\footnotetext{
References

' D' Ardenne AJ, McGee JO' D. Fibronectin in disease. J Pathol 1984; 142: 235-51.

${ }^{2}$ Timpl R, Rodhe H, Gehron-Robey P, Rennard SI, Foidart JM, Martin GR. Laminin-a glycoprotein from basement membranes. J Biol Chem 1979;254:9933-7.

${ }^{3}$ Stenman S, Vaheri A. Distribution of a major connective tissue protein, fibronectin, in normal human tissue. J Exp Med 1978; 147: 1054-64.

${ }^{4}$ Martinez-Hernandez A. The hepatic extracellular matrix. I. Electron immunohistochemical studies in normal rat liver. Lab Invest 1984;51:51-74.

s D' Ardenne AJ, Burns J, Sykes BC, Kirkpatrick P. Comparative distribution of fibronectin and type III collagen in human tissues. J Pathol 1983;141:55-69.

- Yamada KM, Weston JA. Isolation of a major cell surface glycoprotein from fibroblasts. Proc Natl Acad Sci USA 1974;71:3492-6.
} 
' Villiger B, Kelly DG, Kuhn C, McDonald JA. Human alveolar macrophage fibronectin; synthesis and ultrastructural localisation. Clinical Research Forum 1980;28:745A.

${ }^{8}$ Reilly JT, Nash JRG, Mackie MJ, McVerry BA. Immunoenzymatic localisation of fibronectin in normal and pathological haemopoietic tissue. Br J Haematol 1985; 59:497-504.

' Ginsberg MH, Painter RG, Birdwell C, Plow EF. The detection, immunofluorescent localisation, and thrombin-induced release of human platelet-associated fibronectin antigen. Journal of Supramolecular Structure 1979;11:167-74.

${ }^{10}$ Mosesson MW, Umfleet RA. The cold insoluble globulin of human plasma. 1. Purification, primary characterization, and relationship to fibronectin and other cold insoluble fraction components. J Biol Chem 1970;245:5728-36.

"Foidart JM, Bere EW, Yaar M, et al. Distribution and immunoelectron microscopic localisation of laminin, a noncollagenous basement membrane glycoprotein. Lab Invest 1980;42:336-42.

${ }^{12}$ Abrahamson DR, Caulfield JP. Proteinuria and structural alterations in rat glomerular basement membranes induced by intravenously injected anti-laminin immunoglobulin G. J Exp Med 1982; 156: 128-45.

${ }^{13}$ Stenman S, Vaheri A. Fibronectin in human solid tumours. Int J Cancer 1981;27:427-35.

14 Wartiovaara J, Linder E, Ruoslahti E, Vaheri A. Distribution of fibroblast surface antigen: association with fibrillar structures of normal cells and loss upon viral transformation. J Exp Med 1974; 140: 1522-33.

is Liotta LA, Rao CN, Barsky SH. Tumour invasion and the extracellular matrix. Lab Invest 1983;49:636-49.

${ }^{16}$ Rao CN, Barsky SH, Terranova VP, Liotta LA. Isolation of a tumour cell laminin receptor. Biochem Biophys Res Commun 1983;111:804-8.

17 Resnick GD, Nachman RL. Reed-Sternberg cells in Hodgkin's disease contain fibronectin. Blood 1981;57:339-42.

${ }^{18}$ Moller P, Achtstatter H, Butzengeiger M, Schule B. The distribution of fibronectin in lymph nodes infiltrated by Hodgkin's disease. Virchows Arch (Pathol Anat) 1983;400:319-29.

19 Kirkpatrick P, D' Ardenne AJ. Effects of fixation and enzymatic digestion on the immunohistochemical demonstration of laminin and fibronectin in paraffin embedded tissue. J Clin Pathol 1984;37:639-44.

${ }^{20}$ Kurkinen M, Vaheri A, Roberts PJ, Steinman S. Sequential appearance of fibronectin and collagen in experimental granulation tissue. Lab Invest 1980;43:47-57.
21 Crocker J, Smith PJ. Immunohistochemical localisation of factor VIII-related antigen in Hodgkin's disease. J Clin Pathol 1984;37:37-44.

${ }^{22}$ Reilly JT, Nash JRG, Mackie MJ, McVerry BA. Endothelial cell proliferation in myelofibrosis. Br J Haematol (in press).

${ }^{23}$ D' Ardenne AJ, Kirkpatrick P, Sykes BC. Distribution of laminin, fibronectin, and interstitial collagen type III in soft tissue tumours. J Clin Pathol 1984;37:895-904.

${ }^{24}$ Johansson S, Rubin K, Hook M, Ahlgren T, Seljelid R. In vitro biosynthesis of cold-insoluble globulin (fibronectin) by mouse peritoneal macrophages. FEBS Lett 1979;105:313-6.

${ }^{25}$ Colvin RB, Lanigan J, Clark RA, Ebert TH, Verderber E, Hammond ME. Macrophage fibronectin (cold-insoluble globulin, LETS protein). Fed Proc 1979;38: 1408.

${ }^{26}$ Burgorf WHC, Mukai K, Rosai J. Immunohistochemical identification of factor VIII-related antigen in endothelial cells of cutaneous lesions of alleged vascular nature. Am J Clin Pathol 1981;75: 167-71.

${ }^{27}$ Hoyer LW, De Los Santos RP, Hoyer JR. Antihaemophiliac factor antigen; localisation in endothelial cells by immunofluorescent microscopy. J Clin Invest 1973;52:273744.

${ }^{28}$ Jaffe EA, Hoyer LW, Nachman RL. Synthesis of antihaemophiliac factor antigen by cultured human endothelia cells. J Clin Invest 1973;52:2757-64.

${ }^{24}$ Bloom AL, Giddings JC, Wilks CJ. Factor VIII on the vascular intima: possible importance in haemostasis and thrombosis. Nature 1973;241:217-9.

${ }^{30}$ Innes DJ, Mills SE, Walker CK. Megakaryocytic Leukaemia: identification utilising anti-factor VIII immunoperoxidase. $\mathrm{Am}$ J Clin Pathol 1982;77:107-10.

${ }^{31}$ Bloom AL, Giddings JC. Value of factor VIII-related antigen as a means of demonstrating extra medullary megaryopoiesis. $J$ Clin Pathol 1984;37:1317.

32 Jones EL, Crocker J, Gregory J, Guibarra M, Curran RC. Angiofollicular lymph node hyperplasia (Castleman's disease): an immunohistochemical and enzyme histochemical study of the hyaline vascular form of lesion. J Pathol 1984;144:131-47.

${ }^{33}$ Wright DH, Isaacson PC. Biopsy pathology of the lymphoreticular system. London: Chapman and Hall, 1983;203-29.

Requests for reprints to: Dr JT Reilly, University Department of Haematology, Duncan Building, Royal Liverpool Hospital, PO Box 147, Liverpool L69 3BX, England. 